\title{
DEVELOPMENT OF 3D PRINTING RAW MATERIALS FROM PLASTIC WASTE
}

\author{
Alaeddine Oussai ${ }^{1}$ \\ Zoltán Bártfai ${ }^{2}$ \\ László Kátai ${ }^{3}$ \\ István Szalkai ${ }^{4}$
}

DOI: https://doi.org/10.31410/ERAZ.2019.177

\begin{abstract}
Before 40 years, re-utilization of post-buyer bundling as glass containers and jugs was normal. There are restrictions to the excessive and extensive usage of inflexible compartment re-utilization, which are at any rate usually estimated. The dissemination and accumulation focus are generally far away from unified item filling manufacturing plants and would bring about impressive back-pull separations. Also, the extensive variety of compartments and packs for marking and promoting purposes makes coordinate reclaim and refilling less practical. Reclaim and refilling plans do exist in a few European nations (Institute for Local Self-Reliance 2002), including PET containers and also glass, however they are somewhere else for the most part considered a specialty movement for neighbourhood organizations as opposed to a sensible vast scale procedure to lessen bundling waste. (Saikia \& de Brito, 2014). Plastic aggregates used in many studies, prepared from plastic waste, are obtained from different sources. As example plastic bottles were grinded in the laboratory by using a grinding machine and then sieved to get the suitable size fraction. (Frigione, 2010).
\end{abstract}

Keywords: $3 D$ printing, plastic, recycling, extrusion, filament.

\section{INTRODUCTION}

fter studying the applied plastic recycling technologies, materials for 3D printing and the 3D Aprinting technologies, it is realized that the quantity and quality of plastic waste differs from country to country and from company to other. In the case of waste plastics that are recyclable and reusable, the most widely used are polyethylene terephthalate (PET, used for synthetic fibres and water bottles), and second high-density polyethylene (HDPE, used for jugs, bottle caps, water pipes).

The current applications for using recycled plastics in fabrication and design are fairly limited, on a small scale, plastics (such as ABS, HDPE, or PET) are shredded and formed into pellets, and then either extruded into lament to be used in existing 3D printers, or injection moulded into small parts and pieces of larger components. At a large scale, recycled HDPE is melted into sheets and either used directly as sheets in construction, or then heat formed from a sheet into components for construction. These methods of fabrication using recycled plastics are the norm because of their affordability and straightforward processes, yet each method leaves some complexity to be desired.(Al-Salem, Lettieri, \& Baeyens, 2009) recent progress in the recycling and recovery of PSW is reviewed. A special emphasis is paid on waste generated from polyolefinic sources, which makes up a great percentage of our daily single-life cycle plastic products. The four routes of PSW treatment are detailed and discussed covering primary (re-extrusion.

\footnotetext{
Szent István University, Faculty of Mechanical Engineering Institute of Mechanics and Machinery, Hungary Szent István University, Faculty of Mechanical Engineering Institute of Mechanics and Machinery, Hungary Szent István University, Faculty of Mechanical Engineering Institute of Mechanics and Machinery, Hungary FKF Nonprofit ZRT
} 
Regarding the recycling technology, the previous methods of recycling and recovery routes for solid plastic waste are detailed and discussed covering:

- re-extrusion,

- mechanical treatment,

- chemical treatment,

- energy recovery.

Based on the previous research we performed on this field, the main objective of this paper is the contribution to the development of sustainable, effective technologies in the field of plastic recycling, both from the economic and ecological point of view.

Plastics recycling is complex and sometimes confusing because of the wide range of recycling technologies and recovery activities (Hopewell, Dvorak, \& Kosior, 2009). These include four categories: mechanical reprocessing into a product with equivalent properties, secondary mechanical reprocessing into products requiring lower properties, and recovery of chemical constituents (Flores, 2008) and quaternary recovery of energy .Considering recycling technology, the work will be based on Polyethylene terephthalate PET and polylactic acid as mixed polymers PLA.

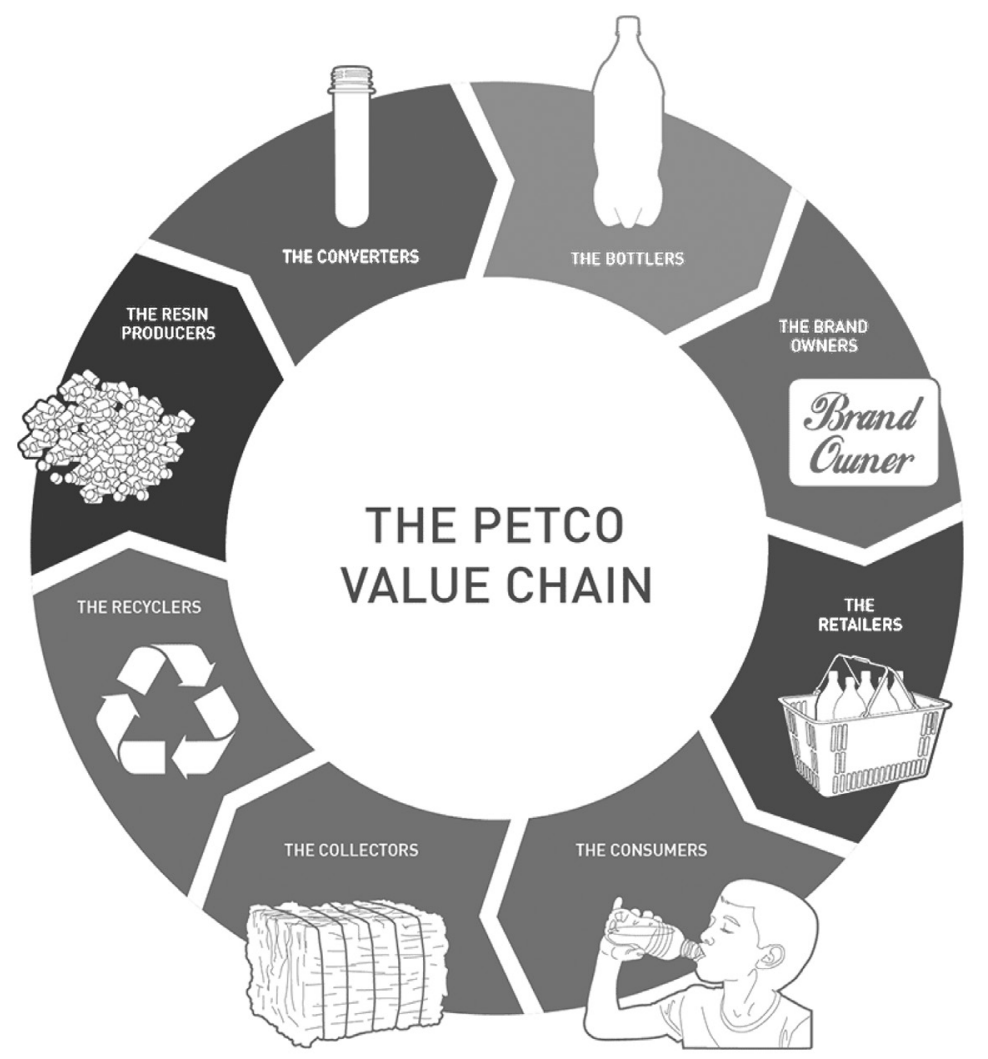

Figure 1. PET recycling circle

\section{RECYCLING PET}

The main production for PET is for the applicability of synthetic fibres (in excess of 60\%) with bottle production accounting for around 30\% of global demand. In terms of textile applications, PET is generally referred to as simply "polyester". The terminology "PET" is used generally used for packaging applications. The polyester industry makes up about $18 \%$ of world polymer production and is third largest industry after polyethylene (PE) and polypropylene (PP). (Rahmani et al., 2013). 
PET composes of polymerized units of the monomer ethylene terephthalate, with repeating $\mathrm{C10H8O} 4$ units. PET is recycled quite frequently and has the number " 1 " as its recycling symbol. The first PET was patented in 1941 by John Rex Winfield, James Tennant Dickson and their employer the Calico Printers' Association of Manchester and the PET bottle was patented in 1973 by Nathaniel Wyeth. PET is also used as substrate in thin film and solar cell.(Bornak, 2013).

As, PET is an excellent barrier material, it is commonly used for producing plastic bottles; especially for the soft drinks. For some special bottles, the PET also sandwiches an additional polyvinyl alcohol for further reducing its oxygen permeability.

Bi-axially oriented PET film (often known by one of its trade names, "Mylar") can be aluminized by evaporating a thin film of metal onto it to reduce its permeability, and to make it reflective and opaque (MPET). The above-mentioned properties hold applications in many domains like the flexible food packaging, thermal insulation for instance for the "space blankets ". Also, it has a high mechanical strength; the PET film is also commonly used in tape applications for example for the carrier of the magnetic tape or backing for the pressure sensitive adhesive tapes.(Welle, 2011).(Tafheem, Islam Rakib, Esharuhullah, Reduanul Alam, \& Mashfiqul Islam, 2018).

The non-oriented PET sheet can undergo thermoforming and used to make packaging trays and blisters. If the crystallisable form of PET is used, it can be used to prepare frozen dinners as they have the capability to withstand the freezing and the oven baking temperatures. Filling these with glass particles or fibres makes them stiffer and durable. (Hopewell et al., 2009)

Table 1 : End markets for PET recirculates in Europe and in the USA (Petcore, 2011; Napcor, 2011).

\begin{tabular}{|c|c|c|c|c|c|}
\hline Year & Percentage fibre & Sheet & Bottle (food, non-food) & Strapping & Other \\
\hline \multicolumn{6}{|l|}{2001} \\
\hline EU & 62 & 16 & 7 & 10 & 5 \\
\hline USA & 62.1 & 5.3 & 17.3 & 11.7 & 3.6 \\
\hline \multicolumn{6}{|l|}{2005} \\
\hline EU & 57.0 & 16.2 & 15.2 & 7.8 & 3.8 \\
\hline USA & 53.6 & 8.2 & 20.6 & 15.2 & 2.4 \\
\hline \multicolumn{6}{|l|}{2009} \\
\hline EU & 40.5 & 27.0 & 22.0 & 7.0 & 3.5 \\
\hline USA & 36.7 & 17.0 & 28.6 & 12.2 & 5.5 \\
\hline
\end{tabular}

\section{RECYCLING MIXED POLYMERS}

Polylactic acid (PLA) and its systems PLA are one of the most vital biodegradable polyesters derived from renewable sources i.e. starch and sugar. Till the last decade, the main applications of PLA were limited to biomedical and pharmaceutical applications such as implant devices, 
tissue scaffolds, and internal sutures due to its high cost and low molecular weight. Since, the existence of both hydroxyl and a carboxyl group in lactic acid allows it to be converted directly into polyesters via a polycondensation reaction; a considerable amount of interest has been paid to the academic research associated with PLA polymer and its copolymers (3e5). Although PLA is a biodegradable material, which would significantly reduce environmental pollution associated with its waste, the knowledge behind this material recycling and changes in the properties of PLA upon its multiple processing is a very important subject of discussion.(Wasan Ismail Khalil \& Khalaf Jumaa Khalaf, 2017).

Polyvinyl chloride (PVC) and its systems along with the low cost and high performance of PVC products combined together with its wide range of properties that can be obtained from different formulations has contributed to the widespread use of PVC in construction products. There has been a long time-lag between PVC consumption and the amassing of PVC waste arising from the long life of PVC products, which can be up to 50 years. It is quite clear that all produced PVC will eventually become waste in a few days' time. The European Association of Plastics Converters (EuPC) has estimated that the PVC waste for the periods between 2010 and 2020 will arise from the following sources. Many works have documented the recycling of PVC and its systems since the beginning of the last decade.(Kou et al., 2009).

Polyethylene's PE's are one of the most widely used plastics characterized by a density in the range $0.918 \mathrm{e} 0.965 \mathrm{~g} / \mathrm{cm} 3$ resulting in a range of toughness and flexibility. Their major application is in packaging film although their outstanding dielectric properties. Chemical recycling of PLA/PE and PLA/PBS blends.

\section{RECYCLING TECHNOLOGIES}

Recent research points the way towards chemical recycling methods with lower energy requirements, compatibilization of mixed plastic wastes to avoid the need for sorting, and expanding recycling technologies to traditionally non-recyclable polymers.

We mentioned the recycling technologies from which we concluded that mechanical recycling is the only widely adopted technology for large-scale treatment of plastic solid waste. The main steps were the removal of organic residue through washing, followed by shredding, melting, and remoulding of the polymer, which is often blended with virgin plastic of the same type to produce a material with suitable properties for manufacturing.

There are limitations to mechanical recycling technologies because each type of plastic responds differently to the process depending on its chemical makeup, mechanical behaviour, and thermal properties. Temperature-sensitive plastics, composites, and plastics that do not flow at elevated temperatures (as in the case of thermosets) cannot be processed mechanically. Consequently, only two types of plastic are recovered and recycled with mechanical processes: poly (ethylene terephthalate) (PET) and polyethylene, which represent 9 and 37\% of the annual plastic produced, respectively. All other plastic solid waste is either not recovered or in amounts representing less than $1 \%$ of production. According to the most recent U.S. Environmental Protection Agency report, a mere $8.8 \%$ of all plastic produced in the U.S. annually is recovered from municipal solid waste and then incinerated, recycled, or industrially composted. The recycling rate is slightly higher in Europe, at $\sim 30 \%$ for plastic waste. 
In our previous research supervised by Dr Zoltán Bártfai, we found solution for grinding and extruding plastic using machines with two different parts: crusher, extruder and mixed it together.

The crusher consisted of 12 blades twelve anvil-blades, right axis, left axis, cover, sieve, fourteen casing spacers, four nuts, two pins and crank. (Oussai, Zoltan, \& Laszlo, 2018).

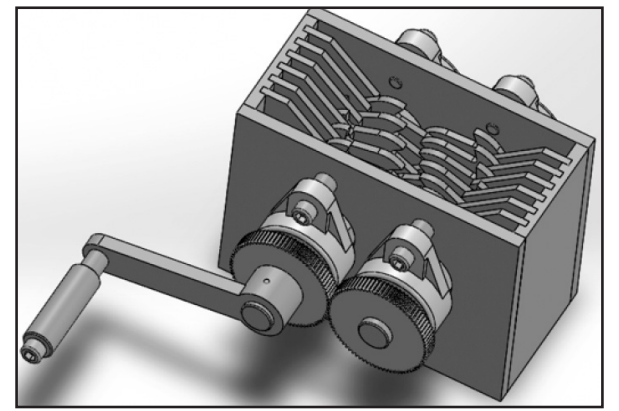

Figure 2. overview of the complete design of the crusher

The extruder consisted of: hopper, room of extrusion, heating collar, chain transmission, nozzle, engine support, engine, control panel and the extruder support. The component which was most important in the extruder was the extrusion screw that acts like a screw pump, fits in the room.

The function of the screw was to move the pieces of plastic inserted through the hopper along the length of the room.

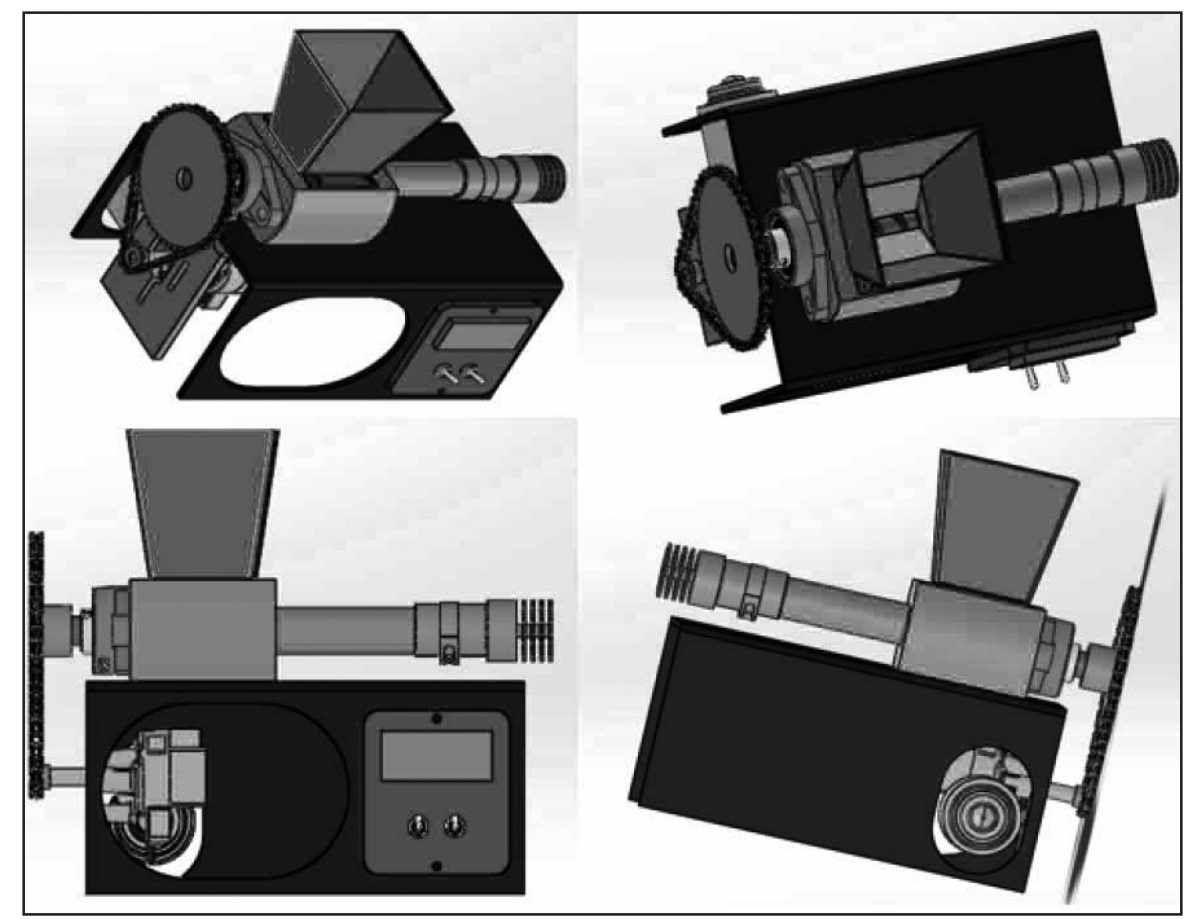

Figure 3. Overview of the complete design of the extruder

Current technologies that move beyond mechanical recycling include pyrolysis (thermolysis) to selectively produce gases, fuels, or waxes through the use of catalysts; are referred to as chemical recycling. Chemical recycling is not a widespread recycling practice, mainly because of energy costs. A further option is the incineration of materials and collection of energy in the 
form of heat. Incineration is convenient for the treatment of mixed waste because it avoids the need for sorting, but it does not allow for the recovery and reuse of the starting components once burned. It also does not save as much energy as recycling.

\section{CONCLUSION}

The environmental consequences of plastic solid waste are visible in the ever-increasing levels of global plastic pollution both on land and in the oceans. But, although there are important economic and environmental incentives for plastics recycling, end-of-life treatment options for plastic solid waste are in practice quite limited. Pre-sorting of plastics before recycling is costly and time-intensive, recycling requires large amounts of energy and often leads to low-quality polymers, and current technologies cannot be applied to many polymeric materials. In the current scenario there is growing demand and interest towards chemical recycling methods with low energy demand along with compatibility of mixed plastic waste to overcome the need for sorting and expanding the recycling technologies to traditional non-recyclable polymers.

\section{REFERENCES}

[1] Al-Salem, S. M., Lettieri, P., \& Baeyens, J. (2009). Recycling and recovery routes of plastic solid waste (PSW): A review. Waste Management, 29(10), 2625-2643. https://doi. org/10.1016/J.WASMAN.2009.06.004

[2] Bornak, R. (2013). Different Methods of PET Production and Its Economy Different Methods of PET Production and Its Economy. European Journal of Scientific Research, (December), 2-3.

[3] Flores, M. C. (2008). Plastic Materials and Environmental Externalities Plastic Materials and Environmental Externalities: Structural Causes and Corrective Policy Table of Contents Plastic Materials and Environmental Externalities Plastics Recycling: Law and Economics. Lethbridge Undergraduate Research Journal, 3, 2-7.

[4] Frigione, M. (2010). Recycling of PET bottles as fine aggregate in concrete. Waste Management, 30(6), 1101-1106. https://doi.org/10.1016/J.WASMAN.2010.01.030

[5] Hopewell, J., Dvorak, R., \& Kosior, E. (2009). Plastics recycling: challenges and opportunities. Philosophical Transactions of the Royal Society B: Biological Sciences, 364(1), 2115-2126. https://doi.org/10.1098/rstb.2008.0311

[6] Kou, S. C., Lee, G., Poon, C. S., \& Lai, W. L. (2009). Properties of lightweight aggregate concrete prepared with PVC granules derived from scraped PVC pipes. Waste Management, 29(2), 621-628. https://doi.org/10.1016/J.WASMAN.2008.06.014

[7] Oussai, A., \& Zoltan, B. (2017). DESIGN AND SIZING OF A PLASTIC RECYCLING STATION INTO FILAMENTS FOR 3D PRINTER. In Engineering, Agriculture and Green Industry Innovation (pp. 1-6). Budapest: synergy international conferences.

[8] Rahmani, E., Dehestani, M., Beygi, M. H. A., Allahyari, H., \& Nikbin, I. M. (2013). On the mechanical properties of concrete containing waste PET particles. Construction and Building Materials, 47, 1302-1308. https://doi.org/10.1016/J.CONBUILDMAT.2013.06.041

[9] Saikia, N., \& de Brito, J. (2014). Mechanical properties and abrasion behaviour of concrete containing shredded PET bottle waste as a partial substitution of natural aggregate. Construction and Building Materials, 52, 236-244. https://doi.org/10.1016/J.CONBUILDMAT.2013.11.049

[10] Tafheem, Z., Islam Rakib, R., Esharuhullah, M. D., Reduanul Alam, S. M., \& Mashfiqul Islam, M. (2018). Experimental investigation on the properties of concrete containing 
post-consumer plastic waste as coarse aggregate replacement | Request PDF. Journal of Materials and Engineering Structures, 5(March), 23-31

[11] Wasan Ismail Khalil, \& Khalaf Jumaa Khalaf. (2017). Eco-Friendly Concrete Containing Pet Plastic Waste Aggregate. Diyala Journal of Engineering Sciences, 10(01), 92-105. Retrieved from https://www.iasj.net/iasj?func=fulltext\&aId $=126163$

[12] Welle, F. (2011). Twenty years of PET bottle to bottle recycling-An overview. Resources, Conservation and Recycling, 55(11), 865-875. https://doi.org/10.1016/J.RESCONREC.2011.04.009 